\title{
Agrochemicals, Suicide Ideation and Social Responsibility
}

\author{
Paulette Andrea Henry \\ Department of Sociology, University of Guyana \\ 95 Amsville Housing Scheme, New Amsterdam, Berbice, Guyana \\ Tel: 592-650-7855/333-2097Ｅ-mail: phenryugbc@yahoo.com
}

Received: July 7, 2015 Accepted: July 27, 2015 Published: October 4, 2015

doi:10.5296/iss.v3i2.7926 URL: http://dx.doi.org/10.5296/iss.v3i2.7926

\begin{abstract}
This paper examines agricultural advancement, agrochemical use, suicide ideation and social responsibility within the agriculture industry in Guyana. Suicide in Guyana is a serious public health problem. The country is ranked fourth in suicides per capita worldwide, with the highest rate amongst South American and Caribbean nations. Suicide is also ranked as the seventh of the ten major causes of death in Guyana. It is the leading cause of death among young people ages 15-24 and the third leading cause of death among persons ages 25-44. A mixed method was used, as documents were reviewed and thematic areas identified. The influence of locality and gender were both examined in this paper, as farmers in rural communities are engaged in both subsistence and commercial agricultural ventures. Some studies have shown a correlation between localities where there was an overexposure to agrochemicals and suicide ideation. Resultantly, the paper articulates that agricultural advancement must have a human face recognizing that the ind ustry that is boosting Guyana's economy is also contributing to the demise of a vital section of its populace. It proposes a tripartite process where all stakeholders -governments, the agrochemical industry and the consumers have a responsibility for furthering clinical research, and commit to a rigorous information, education and communication plan, which also fosters dialogue on the reduction of the dependency on agrochemicals. Highlighting education as a medium for change, the paper suggests that education needs to be more than the writings on labels and must be accompanied by enforceable protocols.
\end{abstract}

Keywords: agrochemicals, gender, suicide ideation, overexposure, social responsibility, suicide prevention 


\section{Introduction}

Guyana has a long history and culture that is linked to agriculture, which is predominantly practiced along the coastal lands. This research paper examines the connection between access to and use of agrochemicals, suicide ideation (Note 1), and social responsibility in the advancement of agriculture in Guyana. Whilst the economy of Guyana is heavily dependent on agriculture which accounts for about $25 \%$ of the Gross Domestic Product (GDP), has contributed to reducing the depth of poverty for the very poor and is the source of livelihood for nearly 35\% of the population (PRSP, 2011; Cariscience, 2014); the corollary is that agrochemicals, heavily used in agriculture production, is also the drug of choice for the majority of persons who commit or attempt suicide. Nonetheless, agricultural growth continues to be the key to poverty alleviation and overall economic development in Guyana.

Notably, suicide in Guyana is a serious public health problem. The country is ranked fourth in suicides per capita worldwide, and has the highest rate amongst South American and Caribbean nations. A WHO/PAHO release in 2012 states that Guyana's has trended high for suicide on several international surveys and though the government has at various times said the problem was being seriously addressed, there have been no observed changes in suicide trends in Guyana. According to PAHO/WHO (2012) suicide was the seventh leading cause of death overall between 2004 and 2006. It was the leading cause of mortality among individuals from 15-24-years old and the third leading cause of death among those 25-44-years old. The highest incidence of suicide attempts and deaths occurred in the 15-24-year age range for females and the 15-34-year age range for males. The prevalence of completed suicides was 24 per 100,000 of the population which was more than twice the average global prevalence, and is likely to be an underestimate (PAHO/WHO, 2012). Importantly, it would appear that a significant majority of persons who commit suicide in Guyana had easy access to agrochemical drugs which is the preferred drug of choice. Moreover, whilst there is the paucity of concrete national data for some periods, oral reports, the media and information gathered from some specific agencies continue to point to the escalation of suicide in recent years.

Several factors can result in suicide ideation and suicide however this discourse will not delve into the reasons for suicide but rather focuses on two key areas: over exposure and social responsibility with social responsibility being viewed as a mechanism for prevention. Resultantly, the discussion that unfolds in this paper centers on the social responsibility of the agrochemical industry at the national and local levels to manage the access to and use of agrochemicals.

When it comes to the use of agrochemicals, both the sellers and users must be very knowledgeable of both the use and management of these chemicals in keeping with the principles of sustainable agriculture. Further, sustainable agriculture requires that success should be indistinguishable from vibrant rural communities, rich lives for families on the farms, and wholesome food for everyone (Ganzi, 2006) and should enable local communities to protect and improve their well being and the environment. 


\section{Rationale}

The consensus of opinion among international and local institutions promotes education and information when it comes to the use of agrochemicals; whereby, both the users and sellers must be very knowledgeable in the use and handling of the chemicals, since sustainable agriculture is also the agriculture of social values. Ganzi (2006) asserts that the idea of integrating Corporate Social Responsibility (CSR) and sustainable agriculture only started to surface as a topic in the $21^{\text {st }}$ Century, and is still not being looked at by most agricultural businesses. Even as the debate in this paper highlights the rise of agrochemicals as the drug of choice in suicide ideation and suicide, the underlying questions which it seeks to answer are twofold. Firstly, is overexposure to agrochemicals a contributory factor to suicide? And secondly are the protocols governing agrochemicals in Guyana managed to ensure compliance? Therefore in analyzing the basic connectives within this investigative approach, the rational concerns of agrochemicals, suicide ideation, suicide, and social responsibility within the agriculture industry in Guyana are justified. The aim of this paper is therefore, to show the correlation between access to agrochemicals, suicide ideation and suicide in Guyana. Recognizing that this issue could be a contentious one, the paper argues that suicide prevention requires corporate social responsibility and posits that sociopolitical action is required to address this public health issue as farmers are guided into making decisions for positive health and sustainable agriculture.

\section{Methodological Approach}

The methodological approach used was both quantitative and qualitative. It entailed, document reviews of protocols, reports of the pest and toxic control beard, media reports and other records. In addition, content analysis of statistical reports of the procurement of agrochemicals, points of sale and data on suicide available were keenly reviewed.

In analyzing the data the researcher looked at trends and a correlation was made between themes such as locality and employment, points of sale and locality as well as suicide by locality and points of sale coupled with an analysis of the monitoring mechanisms. Gender analysis served as a cross cutting theme in the analyses.

\subsection{Limitations}

The researcher was restricted by the paucity of data in this area of study. Apart from WHO's data, updated statistics on suicide were not easily accessible, thereby limiting the data on suicide to police reports in the media and individual health facilities. Additionally, Guyana does not have in place systems to trace and monitor behavioural practices due to overexposure to chemicals. Thus this research does not benefit from that kind of information.

\section{What the Literature Says}

Even outside of commercial agriculture, for decades the culture of Guyana which emerged from a history of enslavement and indentureship has encouraged subsistence farming so that all Guyanese, particularly those in rural areas with more access to land space conduct some form of agriculture pursuit. Notably, rural agriculture has been the "mainstay of the rural 
economy emerging as an indispensable part of agriculture in the world over, offering farmers a wide range of crops in varied topography and climate" (Cariscience, Guiding note 2014).

Specifically, historical data show that in Guyana efforts were made to promote agriculture among Guyanese via the "Grow more food" campaign which served as a part of a bigger national plan in the 1970s to Feed, Clothe and House (FCH) the nation. (Note 2) This is summarized in the National Development Strategy (NDS) strategy which states that Government economic policies during the early 1970s to the mid 1980s emphasized state intervention with the aim of arriving at food self sufficiency (Republic of Guyana, 2000). Although there are no quantifiable data to quantify agrochemicals used during this period, efforts to reduce importation costs suggest that the procurement of agrochemicals would have been done on a needs basis. However, then and now, Guyana's porous borders continue to allow for the illegal importation of illegal chemicals.(Note 3)

Global data show a high correlation between the use of agrochemicals and suicide. The WHO 2012 report states that pesticide poisoning is one of the most common methods of suicide, especially in low- and middle-income countries, and accounts for one-third of the cases globally. Further, analysts cite several factors for the suicides, including crop failure due to agrochemicals and climate change, lower prices due to U.S. farm subsidies, state restrictions on export trade, and the dumping of surplus crops in an oversaturated domestic market (Motlagh, 2008). Poisoning is one of the most common causes of increased morbidity and mortality rates world-wide. Noting that WHO reports highlights that various agents such as pesticides and drugs have been used for intentional and accidental poisoning in different countries, Jesslin et al (2010) in a study in India found that pesticides was the drug of choice for intentional poisoning, with a higher prevalence amongst males. Moreover, developing countries are particularly susceptible due to poorer regulation, lack of surveillance systems, less enforcement, lack of training and inadequate access to information systems. A useful example is India, where pesticides are the most commonly used poisoning agents. Notably however, cases of acute pesticide poisoning (APP) account for significant morbidity and mortality worldwide (Motlagh, 2008).

Whilst there is a growing body of research in Guyana on suicide, (Coultress, 2014 and Thomas 2014), many have looked at ethnicity, social and economic factors and coping strategies, but no clinical assessment has been found that examines whether there is a correlation between suicide, suicide ideation and overexposure to agrochemicals. According to the International Association for Suicide Prevention (IASP) suicide attempts and suicidal ideation are far more common; for example, the number of suicide attempts may be up to 20 times the number of deaths by suicide (Arensman, 2015)

The dangers posed by pesticides in farming are well documented. The FAO acknowledges the risks to crop production posed by pests, and advocates for integrated pest management program (IPM) which have demonstrated that pesticide use can often be reduced considerably without affecting yields or farmer profits. Pesticide risk reduction is further achieved through judicious selection of pesticides and proper pesticide management. The ultimate responsibility is therefore vested in the state to ensure that farmers understand that their 
production will not decline if pesticide use is reduced. Based on a study conducted by Manuweera, Eddleston, Egodage and Buckley (2008) to ascertain whether targeted bans on pesticides reduce yields, the findings have affirmed that countries aiming to apply restrictions to reduce deaths from pesticide poisoning should evaluate agricultural needs and develop a plan that encourages substitution of less toxic pesticides. If farmers have an affordable alternative for pest control for each crop, there is no obvious adverse effect on agricultural output. Roberts, Karunarathna, Buckley, Manuweera and Eddleston. (2004) conducted an assessment on the impact of pesticide regulation on the number of deaths from poisoning in Sri Lanka. These regulations, which were implemented from the 1970s, aimed to reduce the number of deaths - the majority from self-poisoning - by limiting the availability and use of highly toxic pesticides. The import of these pesticides was reduced gradually until they were banned for routine use and there was a corresponding fall in deaths. The findings of the study were instructive and highlighted that Sri Lanka's programmes of pesticide regulation were beneficial. They also highlight that whilst regulations are important for responsibly managing this public health concern, regulations must bear in mind the impact of replacement chemicals and regulations must be implemented alongside other strategies, such as integrated pest management, to reduce the overall pesticide availability for self-harm. This requires the political will of all stakeholders in the sector. Jayasinghe and de Silva (2003) contended that "administrative inertia" is one of the main causes of pesticide problems in Sri Lanka. Where people matter, the state can pave the way for dialogue and action to enforce regulations that reduce importation, and provide training on alternatives.

\section{Findings}

\subsection{Demographics of Agricultural Employment and Suicide in Guyana}

In every administrative region or locality in Guyana, males dominate women in the agriculture sector (Table 1). The largest numbers of male farmers are employed in Regions 2, 3, 4, 5 and 6 which are predominantly agricultural regions. As Table 1 shows, more than 75 percent of the persons engaged in agriculture were men. Immediately, this point to more men having access to agrochemicals and being more exposed to agrochemicals.

Table 1. Gender composition of agricultural employment by locality

\begin{tabular}{lcccc}
\hline Region & Males & Females & Total & Gender disparity \% \\
\hline 1 & 1525 & 438 & 1963 & 77.69 \\
2 & 3144 & 341 & 3485 & 90.22 \\
3 & 7547 & 470 & 8017 & 94.14 \\
4 & 6652 & 838 & 7490 & 88.81 \\
5 & 4360 & 178 & 4538 & 96.08 \\
6 & 11343 & 605 & 11948 & 94.94 \\
7 & 1024 & 504 & 1528 & 67.02 \\
8 & 645 & 149 & 794 & 81.23 \\
9 & 2863 & 1057 & 3920 & 73.04 \\
10 & 1743 & 189 & 1932 & 90.22 \\
\hline
\end{tabular}

Source: Bureau of Statistics - Population Census 2002 


\section{Macrothink}

Issues in Social Science

ISSN 2329-521X

2015, Vol. 3, No. 2

It is important to note that the findings show that there is a high correlation between the agricultural employment and suicide. In data extracted from the records posted by the Guyana Police Force for 2013,

Table 2 shows that suicide fatalities are more prevalent in regions in which the primary economic activity is agriculture and where there are more rural and subsistence farming communities than in urban Guyana.

Table 2. Suicide occurrence by region in Guyana for the year 2013

\begin{tabular}{|c|c|c|c|c|}
\hline Region / Poce Divisions & $\begin{array}{c}\text { Administrative } \\
\text { Regions } \\
\end{array}$ & $\begin{array}{c}\text { Main Economic } \\
\text { Activity } \\
\end{array}$ & $\begin{array}{c}\text { No. of } \\
\text { fatalities }\end{array}$ & $\%$ \\
\hline $\begin{array}{l}\text { A Division - Georgetown/ } \\
\text { East Bank Demerara }\end{array}$ & 4 & $\begin{array}{l}\text { Service activities and } \\
\text { subsistence agricultural }\end{array}$ & 20 & 18.3 \\
\hline $\begin{array}{l}\text { B Division - East Berbice } \\
\text { Corentyne }\end{array}$ & 5 and 6 & $\begin{array}{c}\text { Commercial and } \\
\text { subsistence agriculture }\end{array}$ & 36 & 33.0 \\
\hline $\begin{array}{l}\text { C Division - East coast } \\
\text { Demerara }\end{array}$ & 4 & $\begin{array}{l}\text { Service activities and } \\
\text { subsistence agriculture }\end{array}$ & 20 & 18.3 \\
\hline $\begin{array}{l}\text { D Division - West } \\
\text { Demerara / East Bank } \\
\text { Essequibo }\end{array}$ & 3 & $\begin{array}{l}\text { Commercial } \\
\text { agriculture }\end{array}$ & 12 & 11.0 \\
\hline $\begin{array}{l}\text { E Division }- \text { Linden } \\
\text { /Kwakwani }\end{array}$ & 10 & Mining and service & 1 & 0.9 \\
\hline F Division - Interior & $1,7,8$ and 9 & $\begin{array}{c}\text { Mining, forestry, } \\
\text { subsistence agriculture }\end{array}$ & 13 & 11.9 \\
\hline $\begin{array}{l}\text { G Division - Essequibo } \\
\text { Coast and Islands }\end{array}$ & 2 & $\begin{array}{l}\text { Commercial } \\
\text { agriculture }\end{array}$ & 7 & 6.4 \\
\hline Total & & & 109 & \\
\hline
\end{tabular}

(Source: Republic of Guyana. Ministry of Agriculture, 2014)

Administrative Regions 5 and 6 which are considered the largest agricultural regions for both commercial and subsistence agriculture, continue to record the highest number of suicide. Of note too is that areas where subsistence farming occurs, there is also a higher incidence of suicide. Specifically, data retrieved from the primary hospital that serves Regions 5 and 6 show the increasing spiral in suicide attempts in these regions between 2009 and 2013 with a marginal decline in 2013. The same trends persisted for fatalities, with 2012 recording the highest prevalence in both attempts and fatalities (See Table 3). Moreover, the hospital records also show that the majority of the fatalities (73 percent) were as a result of the injection of poisonous substances (See Figure 1). 


\section{Macrothink}

Issues in Social Science

ISSN 2329-521X

2015, Vol. 3, No. 2

Table 3. Persons attempting and committing Suicide at New Amsterdam Hospital 2009-2013

\begin{tabular}{lll}
\hline & & Number \\
Year & Attempted & Fatalities \\
\hline 2009 & 65 & 21 \\
2010 & 90 & 18 \\
2011 & 80 & 17 \\
2012 & 150 & 20 \\
2013 & 113 & 16 \\
Total & 498 & 92 \\
\hline
\end{tabular}

Source: Records from New Amsterdam Hospital

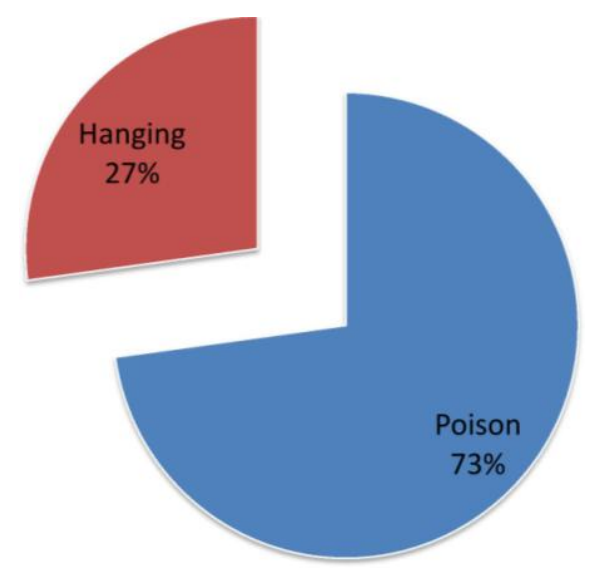

Figure 1. Mode of suicide recorded at the New Amsterdam Hospital (Region 6) for the period 2009-2013

Source: Records from New Amsterdam Hospital

Growth of Agrochemical Industry in Guyana and Suicide

In Guyana, rapid agricultural growth continues to be the key to poverty alleviation and overall economic development and has been successful in keeping pace with the rising food demand of the country and the Region as a whole (Cariscience, 2014). Growth and development in agriculture is concomitant with growth of the agrochemical industry. Table 4 shows the stark hike in pesticides importation between 2006 and 2013. This trend is consistent with patterns noted since 2004 (See Figure 2). 


\section{Macrothink}

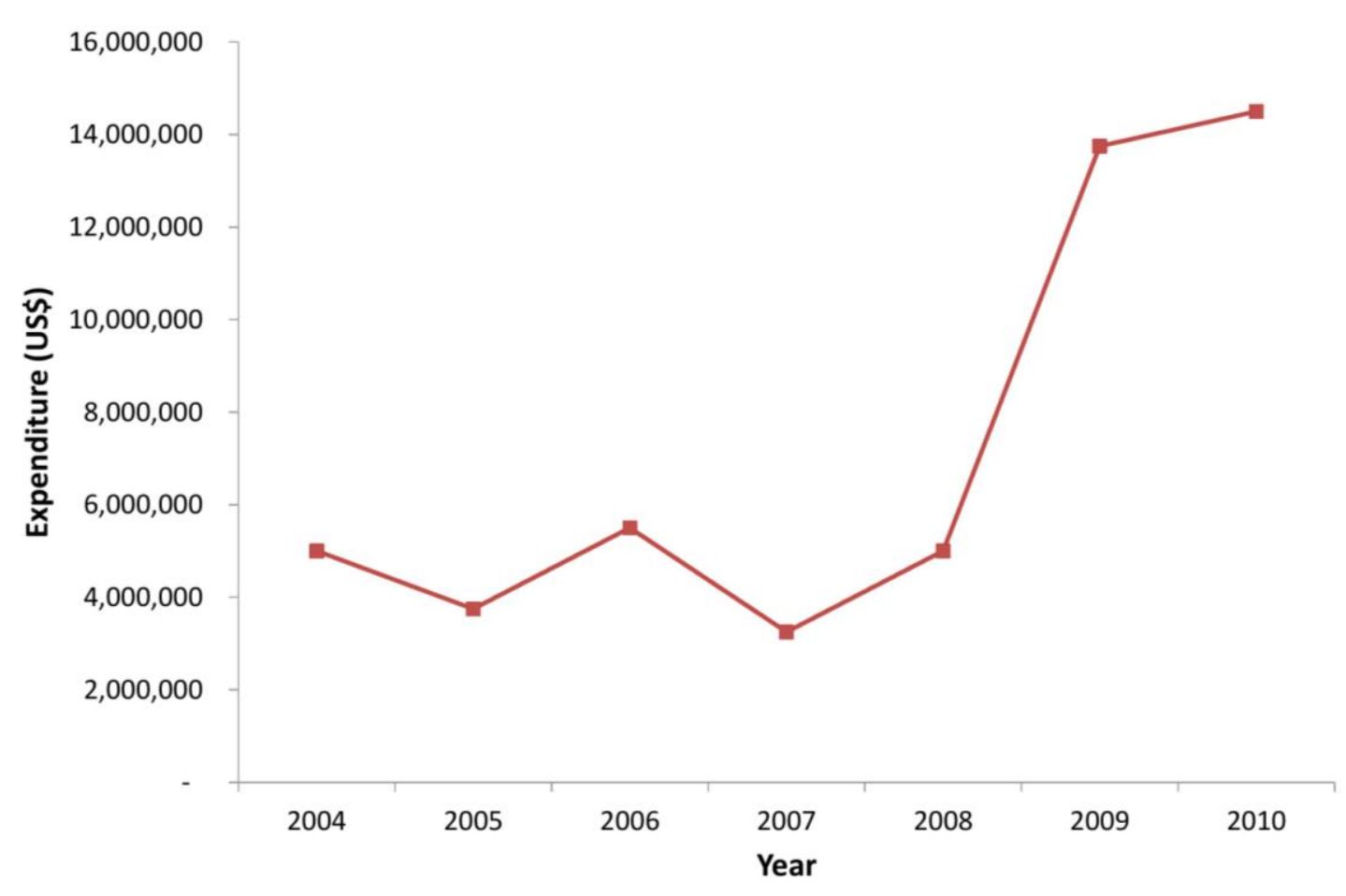

Figure 2: Expenditure on the importation of pesticides from 2004-2010

Source: Annual report PTCCB, 2010

Increases in pesticide importation costs suggest that the use of agrochemicals is heavily tied to the agricultural crop protection and increase in crop production. The total import value of pesticides imported for 2013 was approximately seventeen million one hundred and eight thousand six hundred and seventeen United States Dollars (USD 17,108,617.54). This contrasts with an importation cost of USD 3,081,079.35 in 2006. Concomitantly, the Pesticide Toxic Chemical Control Board (PTCCB) certified ninety two (92) vending premises in 2006 and one hundred and thirty one (131) in 2010, an increase by 39 or 30 percent, and by 2013 there were one hundred and sixty eight (168) vending premises for the year. This represents an increase in the number of premises from 2012 by fifteen (15). The types of drugs and moneys expended for the importation of drugs also keeps escalating. 
Table 4. Pesticides and respective value by category

\begin{tabular}{lcc}
\hline Pesticide Category & \multicolumn{2}{c}{ Expenditure } \\
\cline { 2 - 3 } & $\mathbf{2 0 0 6}($ USD) & $\mathbf{2 0 1 3}($ USD) \\
\hline Insecticides & $1,163,915.00$ & $3,509,740.97$ \\
Herbicides & $1,550,960.00$ & $4,116,820.71$ \\
Fungicide & $32,180.00$ & $319,333.46$ \\
Rodenticides & $148,825.00$ & $67,837,489.98$ \\
Molluscicide & & $14,394,210.00$ \\
Toxic Chemicals & $37,041,000$ & $78,902,052.00$ \\
Total & $616,216,000$ & $1,750,312,779.52$ \\
\hline
\end{tabular}

Source: Republic of Guyana. Pesticides and Toxic Chemicals Control Board, 2007-2013, Concomitantly

Table 5 shows the points of sale for agrochemicals and suicide by region. An analysis was made of points of sale and suicide fatalities for the year 2009. The correlation between the number of sale points for agrochemicals and the number of suicide cases per region was tested using the Pearson's Correlation test. The results indicated a correlation coefficient of 0.61 which suggests a moderate positive relationship between points of sale for agrochemicals and number of suicide cases in Guyana. More specifically the results imply that the increase in agrochemical sale points in the respective regions results in a corresponding increase in suicide fatalities. The 2009 data show that Suicide and even attempts at suicide were lower in four regions (1, 7,8 and 9) and only accounted for 6.8 percent of the suicide fatalities in the country in contrast to three regions $(4,5$ and 6$)$ where the bulk of fatalities occurred, 73.8 percent.

Table 5. Comparison of number of sale of agrochemicals and regional suicide numbers within Guyana

\begin{tabular}{lcc}
\hline Regions & Points of sale for Agrochemical & Number of Suicides in 2009 \\
\hline $1,7,8$ and 9 & 0 & 7 \\
2 & 40 & 7 \\
3 & 17 & 12 \\
4 & 29 & 40 \\
5 and 6 & 42 & 36 \\
10 & 3 & 1 \\
\hline
\end{tabular}

Source: Annual Report PTCCB, 2013/Ministry of Health, 2009 Statistics Bulletin 


\section{Macrothink}

Issues in Social Science

ISSN 2329-521X

2015, Vol. 3, No. 2

\subsection{Trend Analysis}

It is evident that the increase in the use of agrochemicals is heavily tied to the agricultural crop protection and increase in crop production The Guyana Pesticide and Toxic Chemicals Control Act of 2002 as a regulatory body stipulates the proper management of pesticides yet agro chemicals are easily accessible to farmers. The data continue to show that suicide in Guyana seems to be inherently linked to the growth of the agro chemical industry and as shown in Figure 1, more than 70 percent of the fatalities were due to the ingestion of poisons. Whilst there continues to be a paucity of holistic data on suicide, there is enough data as to arouse concerns. The WHO mortality database reveals that in 2008 there were 157 suicides and 169 in 2009, an increase of 18 percent. In 2008, 124 suicides were committed by males. In the subsequent year, the number of male suicide deaths decreased to 109.

Further reviews of suicide trends for the period 1988 to 2009 shows a steady increase in reported cases of suicide, the most significant increase observed during the period 1998-2001 (Figure 3).

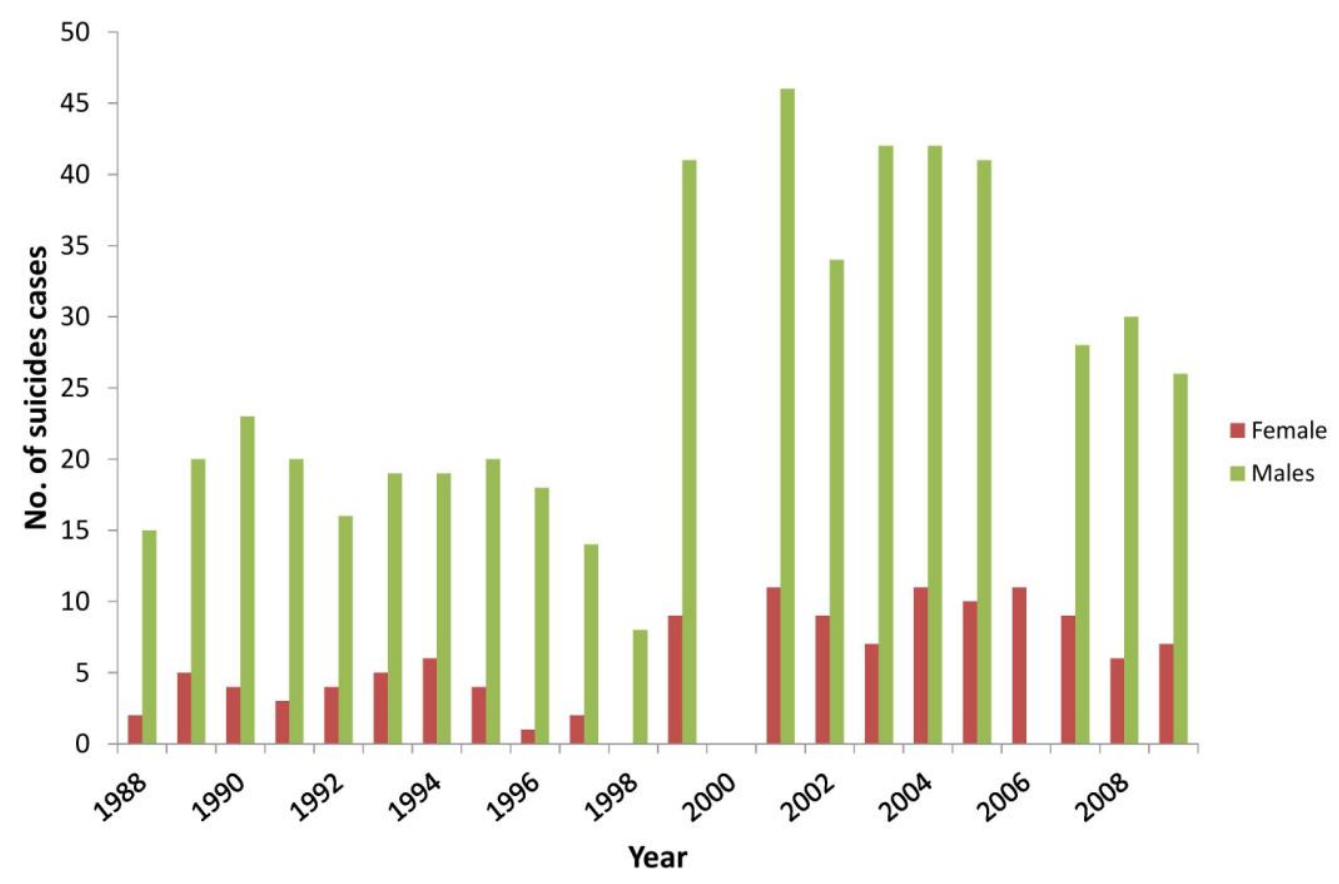

Figure 3: Comparison of suicide rates by gender for persons between ages 15-54 years Source: World Health Organisation, 2014

A linear projection of suicide numbers based on the trend from 1988 to 2009, shows that the annual reported cases of suicide, if left unmonitored, could increase to more than 300 by the year 2025, with an annual average number of approximately 272 cases of suicide deaths for the period 2016-2025 (See Figure 4). 


\section{Macrothink}

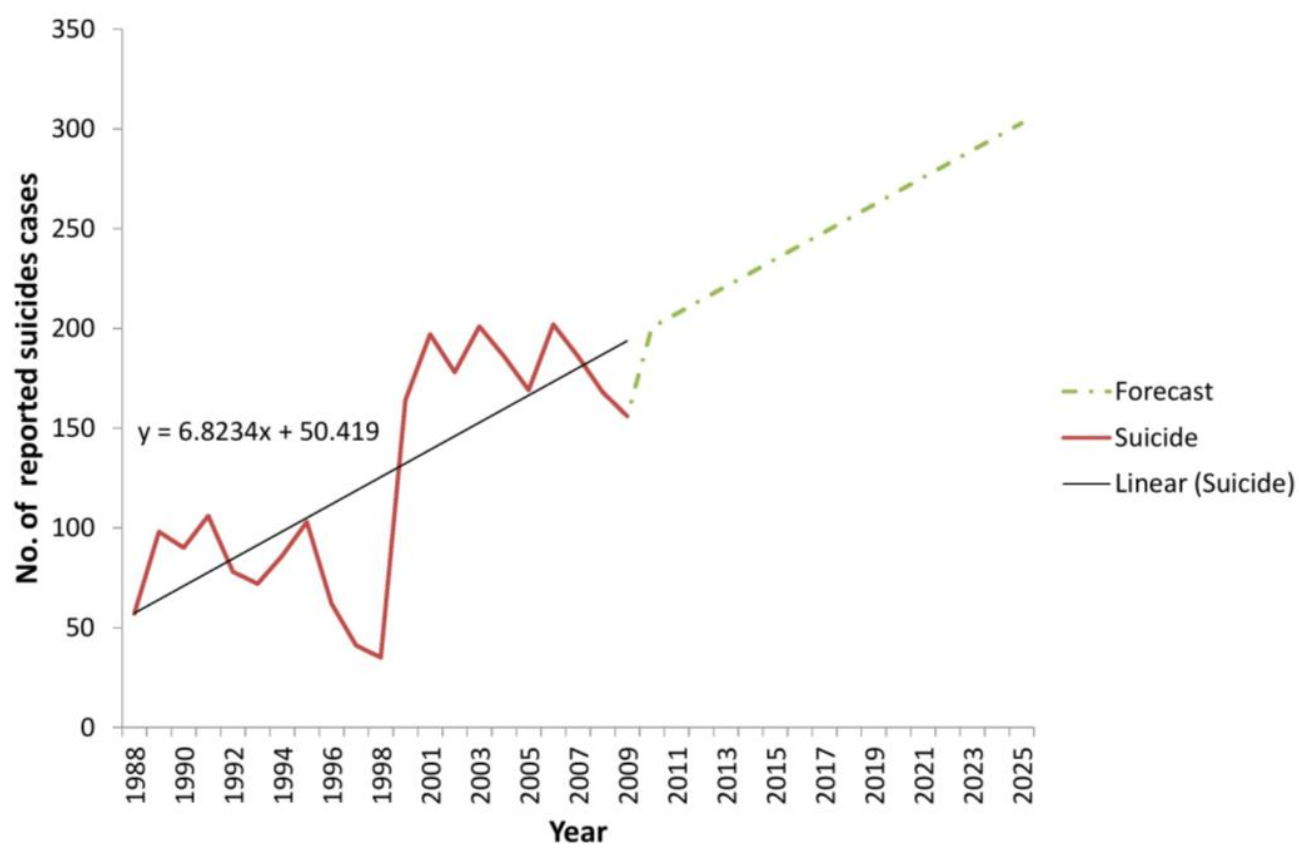

Figure 4. Current and projected suicide trends in Guyana

Source: World Health Organisation, 2014

Table 6 shows a similar increasing trend in suicide rates (number of suicides per 100,000 persons) when compared with the numbers of suicide cases reported. This suggests that the observed increase in the number of suicide cases was not influenced by the population size.

Moreover, a review of data on causes of suicide shows that more than 70 percent of suicides in Guyana during the period 2009-2013 were committed through the use of poison substances which were primarily agrochemicals (Figure 1). The alternative method to suicide was hanging.

\subsection{Gender Analysis}

What the data already shows is that more men than women ingested agrochemical drugs. This is very similar to intentional poisoning observed more in male population by Jesslin et al (2010). Females tend to show higher rates of reported nonfatal suicidal behaviour and when assessed by completed suicide and gender, as shown in Table 6, men have a much higher rate of completed suicide which may further suggest that more men may have suicide ideation than women. 


\section{Macrothink}

Table 6. Gender and Suicide rates in Guyana 1977- 2006

\begin{tabular}{lccc}
\hline Year & Total & Male & Female \\
\hline 1977 & 0.0 & 0.0 & 0.0 \\
1984 & 1.4 & 1.7 & 1.1 \\
1990 & 12.4 & 18.1 & 7.0 \\
1995 & 13.9 & 22.0 & 6.3 \\
2001 & 26.8 & 42.9 & 11.4 \\
2005 & 22.9 & 33.8 & 11.6 \\
2006 & 26.4 & 39.0 & 13.4 \\
\hline
\end{tabular}

Source: PAHO/WHO, 2012

The findings also suggest a correlation by gender and overexposure to agrochemicals since more men are exposed based on their employment in the sector, and seems to have a greater tendency to suicide ideation and completed suicide. Figure 2 shows an increasing trend in the number of suicides in each gender with a sharper increase among males. Throughout the period 1988 to 2009 the number of suicides recorded among males were higher than suicides among females. This trend is persistent today.

\subsection{Management of the Agro Chemicals Sector}

Guyana has in place several mechanisms to manage the agrochemical industry. The data shows that there are seventeen pieces of key legislation addressing the management of chemicals, wholly or partially, in Guyana. These legislations are enforced under different agencies such as the Pesticides and Toxic Chemicals Control Board (PTCCB), Ministry of Labour, the Food and Drug Department of the Ministry of Health, the Guyana Geology and Mines Commission, the Guyana Energy Agency, the Ministry of Home Affairs, the Environmental Protection Agency, and the Ministry of Trade. Generally, the overlapping of responsibilities is resolved through appropriate Memoranda of Understanding between or among the relevant agencies. However, enforcement of existing legislation is often difficult due to limited human resources and bud getary constraints which are not unique to developing countries like Guyana. Additionally, understaffing contributes to inadequate chemical management within some institutions. Of significance, awareness concerning chemical safety matters remains weak both among the public in general and many decision makers, but there exists educational and training programmes related to chemical management. Civil society, in cooperation with government and the private sector, including the communications media, have a crucial role to play in improving public awareness and educating various users of chemicals in the society since a large number of young people commit suicide each year.(Note 3)

Of note too, is the need for institutional capacity building and strengthening within the respective Governmental institutions, especially pertaining to the regulatory and emergency response aspects of chemical management especially in the areas of chemical safety; poisoning prevention and treatment; environmental management; toxicology; epidemiology; 
risk analysis; logistics; conventions and international agreements; and socioeconomic and policy analysis. These will all attest to a socially responsible sector that ensures safe and sustainable agriculture.

As the agrochemical industry in Guyana continues to expand, government seeks through the PTCCB to ensure that it is compliant with the 2007 Stockholm Convention on persistent organic pollutants via its Pesticide Toxic and Chemicals Control implementation plan. Additionally, the Board certified one hundred and sixty eight vending premises for the year 2013. This represents an increase in the number of premises from the previous year (2012) by fifteen (15).

\subsection{Social Responsibility and the Agriculture Industry}

All of the annual reports examined from 2007 to 2013 indicate the conduct of staff training, farmer education and even education in schools with one week of activities set aside for Pesticide Awareness Week are all activities geared towards public education. Despite these initiatives, awareness concerning chemical safety matters remains weak both among the public in general and many decision makers. Civil society, in cooperation with government and the private sector, including the communications media, have a crucial role to play in improving public awareness and educating various users of chemicals in the society.(Note 4) Noting the magnitude of the problem, the PTCCB has indicated that getting persons to change habits which included the dependency on agrochemicals for about 20-30 years, the Board has identified as a major challenge. Despite this recognition of the dependency on agrochemicals and the public awareness programs, there has been no clearly defined strategy that points to re-education programs for stakeholders who are dependent on the industry particularly at the subsistence level for their livelihoods.

Another critical factor for Guyana is that despite the stark increase in legitimate agrochemicals imports which are easily accessible to farmers, there is also the underground economy which allows the entry of illegal importation due to Guyana's inability to properly manage its borders. The Business Sector which includes the Private Sector Commission and the Chambers of Commerce are amongst the agencies which assist in engendering social responsibility as the agrochemical industry falls within the private sector.

Notably, whilst suicide is an important factor that needs to be addressed by the industry, and is the key factor of this paper since it addresses human health, there are a range of other issues which are being generated by the growth in the use of the agrochemicals in Guyana. These include food safety as well as the impact of these chemicals upon the environment. This has been corroborated by the FAO (2014) which advocates that economic growth and agricultural inputs must consider the important forms of human behaviour especially risk management, global food systems, and their corresponding regional and international agreements. They also recommended that social and economic responsibilities become complementary in developing nations, and most of these countries should consider investing more in their health and humans capacities, and find sustainable ways of lowering the use of agricultural inputs towards a climate - smart future. 


\section{Macrothink}

Issues in Social Science

ISSN 2329-521X

2015, Vol. 3, No. 2

With all of the evidence pointing to the negative impact which the increasing growth of the agrochemical industry seems to be having on human life, there is the need for a concerted approach geared towards suicide which is a public health issue and which should target rural farming communities. A tripartite approach is proposed in Figure 5. This approach will result in constructive engagements with the government, consumers and the agrochemical industry.

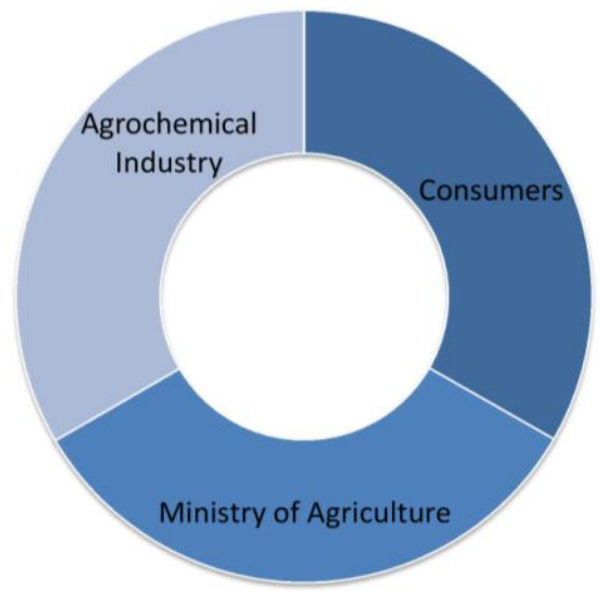

Figure 5: A tripartite approach to chemical management

Although this paper has steered away from the other risk factors which may contribute to suicide ideation and suicide, it is important to note that those engaged in the farming industry have recognized that whilst they can have a successful yield, this may not always be consistent due to either natural disasters such as floods, extended dry spells or diseases. These may have catastrophic results with corresponding social and economic impacts. Coping with these impacts can be stressful. Further, farmers in Guyana have been known to suffer from delayed payment, especially where farmers may have taken loans to promote their business, a catastrophic result and other delays coupled with family commitments and also can heighten their stress. There are no structured social support systems for combating catastrophic experiences in the agriculture industry. The absence of stress management guidance for farmers coupled with the ease of access to drugs is an important factor that must be considered in the sustainable agriculture.

\section{Conclusion}

This study has shown that there is a direct correlation between overexposure to agrochemicals suicide ideation and suicide. Moreover, it clearly highlights suicide fatalities by gender since men, who are predominantly employed within the industry in both commercial and subsistence farming primarily in rural communities, are more prone to suicide fatalities than women. There is therefore the need for traceability and behaviour surveillance studies that would provide greater clarity on this issue, allowing for a better understanding of overexposure of agrochemicals to human health.

The rapid increase in the procurement of agrochemicals which accounts for billions of dollars over the last decade coupled with the ease of access seems to be inherently linked to the continued increase of suicide since the data for Guyana shows that agrochemicals is the preferred drug of choice for persons inflicting self harm. The findings in this study are very 
similar to that of other countries like Brazil, China and Sri Lanka as alluded to earlier. Important too, agrochemical management requires that staff should have the capacity to manage the sector. All reports point to deficiency in capacity to undertake chemicals management mandates. This understaffing, and the fact that individuals often have several other duties in addition to their chemical management responsibilities, is a significant constraint on the effective functioning of the national chemicals management infrastructure.

Further, the findings prescribe a need for corporate social responsibility for safe and sustainable agriculture. Concomitantly, there will be the need to review the demand for the use of agrochemicals. Education has to be a major factor in the process of change. Education is necessary but must cater for re-education on how to use less toxic chemicals in farming. A tripartite arrangement amongst key stakeholders is proposed. Important too, resources for the enforcement of protocols must be addressed with urgency especially since unclear decentralization mechanisms and monitoring may be contributory factors to ease of access. Additionally, studies to guide the use of less toxic drugs potentially leading to change in regulations are necessary. Although legislations is characterized with some level of regulatory and emergency response provisions, public participation in environmental decision - making could increase awareness on public health and the integration of views from the populace on matters of the environment, human health, nutrition, research, and testing by augmenting future attempts at drafting legislations, and by including all of the critical areas that contribute to suicide and suicide ideation.

There is a general consensus in the reviewed documents that support within farming communities in the form of community health assessments is necessary to assess the mental health of farmers, since the inherent risks to farmers from agrochemicals could serve as precipitating factors for suicide ideation and suicide. These can be facilitated through strengthened support services at hospitals and rural health services.

An important factor that this exploratory study has highlighted is the need for further clinical studies to ascertain the correlation between overexposure and suicide. It also serves as a platform for encouraging the Ministry of Agriculture, the University and other schools of agriculture to increase awareness and use as best practices non-toxic ways of increasing farm yield. The time to take action to address suicide and its impact is most compelling given Guyana's standing on the world suicide record. This requires corporate leadership calling on policy makers, civil society and those involved in the agricultural industry at all levels to tackle the problem. Suicide is preventable and requires collective action.

\section{References}

Acton, Q. A. (2012). Agrochemicals: Advances in Research and Application 2012 Edition. Atlanta, Georgia: Scholarly Editions.

Arensman, E. (2015). IASP Congress Montreal 2015, More than two decades after Montreal 1993. International Association for Suicide Prevention (IASP). [Online] Available: https://www.iasp.info/

Basnyat, B. (2003). Minimum pesticide list for the developing world. The Lancet, 361(9353), 259-260. http://dx.doi.org/10.1016/S0140-6736 (03)12292-1 


\section{Macrothink}

Issues in Social Science ISSN 2329-521X 2015, Vol. 3, No. 2

Cariscience. (2014, August). Recent Advances is Soil and Disease Management in Crop Production - "Issues and Challenges, Towards Sustainable Production Practices". Symposium conducted at Cariscience General Annual Meeting for the Guyana Rice Producers Association. University of Guyana. [Online] Available: http://www.uog.edu.gy/?q=notice/cariscience-general-annual-meeting-national-symposium

Coultress, S. (2014). An exploratory study of the underlying factors and problematisations of suicidality in Guyana. Unpublished.

Food and Agricultural Organisation. (2014). The State of Food and Agriculture. [Online] Available: http $/ /$ www.fao.org/3/a- i4040e.pdf

Ganzi, J. (2006). Sustainable Agriculture, Corporate Social Responsibility (CSR) \& the Private Sector of the Financial Services Industry. Organisation of American States. [Online] Available: http $/ /$ www.oas.org/dsd/.../trade/.../paper\%2011-22\%20final\%20paper.pdf

Jesslin, J., Adepu, R., \& Churi. S. (2010). Assessment of Pre valence and Mortality Incidences Due to Poisoning in a South Indian Tertiary Care Teaching Hospital. Indian Journal on Pharmaceuticals Sciences, 72(5), 587-591. http//dx.doi.org/10.4103/0250-474X.78525

Josef G. T., Stober, J., Besbelli, N. and Pronczuk, K. (2008). Acute pesticide poisoning: a proposed classification tool. Bulletin of the World Health Organisation, 86(3), 161-240. Retrieved from http//www.who.int/bulletin/volumes/86/3/07-041814/en/

Manuweera, G., Eddleston, M., Egodage, S., \& Buckley. N. A. (2008). Do targeted bans of insecticides to prevent deaths from self-poisoning result in reduced agricultural output? Environ Health Perspect, 116(4), 492-495. http://dx.doi.org/10.1289/ehp.11029

Motlagh. J. (2008, March 22). India's Debt-Ridden Farmers Committing Suicide. The San Francisco Chronicle. Retrieved from http//www.sfgate.com.

Pan America Health Organisation / World Health Organisation. (2012). Health in the Americas 2012 Edition - Regional Outlook and Country Profiles. Country Volume. Retrieved from http://www.paho.org/saludenlasamericas/docs/hia-2012-summary.pdf

Republic of Guyana. (2010). Poverty Reduction Strategy Paper 2011-2015.

Republic of Guyana. Bureau of Statistics. (2003). 2002 Population Census.

Republic of Guyana. Ministry of Agriculture. (2014). Annual Report.

Republic of Guyana. Ministry of Health. (2014). Draft A National Mental Health Strategy for Guyana (2015-2020). Retrieved from http://www.health.gov.gy/index.php/programmes /disease-control/mental-health/strategies/draft-strategy-2015-2020

Republic of Guyana. National Development Strategy Secretariat. (2000). National Development Strategy (2001-2010). Retrieved from http://www.sdnp.org.gy/nds/ 


\section{Macrothink

Republic of Guyana. Pesticides and Toxic Chemicals Control Board. (n.d.). Annual Report 2007. Retrieved from http://www.ptccb.org.gy/newsandreports/annualimports/annualreports 2007.pdf

Republic of Guyana. Pesticides and Toxic Chemicals Control Board. (n.d.). Annual Report 2009. Retrieved from www.ptccb.org.gy/documents/Annual\%20Report\%202009.pdf

Republic of Guyana. Pesticides and Toxic Chemicals Control Board. (n.d.). Annual Report 2011. Retrieved from www.ptccb.org.gy/.../Annual\%20Report\%202011\%20PTCCB.pdf

Republic of Guyana. Pesticides and Toxic Chemicals Control Board. (2014). Annual Report 2013. Retrieved from http://www.ptccb.org.gy/.../Annual\%20Report\%202013\%20 Ptccb\%20(Final)\%

Republic of Guyana. Pesticides and Toxic Chemicals Control Board. (n.d.) Annual Report 2006. Retrieved from http://www.ptccb.org.gy/newsandreports/annualimports/ANNUALREP ORT2006.pdf

Republic of Guyana. Pesticides and Toxic Chemicals Control Board. (n.d.) Annual Report 2008. Retrieved from http://www.ptccb.org.gy/documents/ANNUALREPORT2008.pdf

Roberts, D. M., Karunarathna A., Buckley N. A., Manuweera G, \& Eddleston M. (2003). Influence of pesticide regulation on acute poisoning deaths in Sri Lanka. Bull World Health Organ, 81(11), 789-798.

Thomas, S. (2014, March15). AUOR study finds suicide is a grave problem. Guyana Chronicles. Retrieved from http://guyanachronicle.com/auor-study-finds-suicide-is-a-grave -problem/

Unliver and Sustainable Agriculture. (2005). Growing for the Future. [Online] Available: http://www.Unilever.com/ourvalues/environmentandsociety/env_social_report/sustainibility

Vetro, A., Sun, H., DaGraca, P., \& Poon, T. (1998). Minimum drift architectures for three-layer scalable DTV decoding. IEEE Trans. Consumer Electron, 44(3), 527-536. http://dx.doi.org $/ 10.1109 / 30.713160$

World Health Organisation. (2014). Country data - Mortality. [Online] Available: http://www.who.int/en/ database 